\title{
The Principle and Application of Intelligent Machine Tools Qinghui Dai ${ }^{1, a}$, Xiaomin Wang ${ }^{1, b}$ \\ ${ }^{1}$ Department of Mechanical Engineering, North China Electric Power University, Baoding, Hebei 071003, China \\ adcba6789@126.com, b18331126618@163.com
}

Keywords: Intelligent machine tools, Intelligent CNC machine tools framework, Application.

\begin{abstract}
Intelligent machine tools are fundamental to realize manufacturing technology and equipment modernization, and are the workhorses of modern equipment in the manufacturing industry, and are of great significance for the further research of intelligent machine tools. A framework of intelligent numerical control system is put forward through the research on the structure of two kinds of intelligent numerical control system. Finally, this paper will summarize the development trend of intelligent machine tools.
\end{abstract}

\section{Introduction}

The development goals of machine tool technology are to be able to realize the comprehensive automation of equipment manufacturing industry, and to create more wealth for mankind. In the process of comprehensive automation of equipment manufacturing industry, the problem that to be solved is how to replace the manual and mental labor with intelligence. The emergence of intelligent machine creates conditions for comprehensive production automation of equipment manufacturing industry.

In the 1960's, the adaptive control machine tool was proposed by American [1], but the development was slow. In 1962, the Bendix Corporation in the United States succeed in adaptive control optimization (ACO) on CNC milling machine for the first time, designed to achieve the best condition of evaluation index with adjusting the cutting parameter. In the international manufacturing technology exhibition in 2006 (IMTS 2006), the Okuma and Mazak corporation of Japan's showed the numerical control Machine tools named after "THINC" and "Intelligent Machine" respectively. In 2012, VDM discussed the technology of machine tool in the seminar of machine tool technology in Guangzhou, China [2]. It was expected that we will approach the adaptive control of the single machine tools, and gradually success in the development of manufacturing systems, and have the potential to build the intelligent factory of the technical level of the different degree of intelligence in the 21 st century.

To the end, in order to provide references for the future development of intelligent machine tools research, this paper expounds the principle and application of intelligent machine tools.

\section{The Principle of Intelligent Machine Tools}

The Concept of Intelligent Machine Tools. Intelligent machine tools are a kind of machine tool which can make judgment and decision to manufacturing processes. Although there is no clear definition for intelligent machine tools at present, based on the researches at home and abroad, we make the interpretation as follows: Intelligent Machine tools is a kind of machine tool which can monitors and analysis automatically information related to processing procedure, environment and the information itself. It is processing machinery which can achieve the optimal behavior under the uncertainty environment and its changes.

It should be pointed out that, the automatic monitoring of the intelligent automatic machine tools includes perception, monitoring, adjustment and maintenance, they are all done automatically. Analysis information by itself is the basis of making judgments of intelligent machine tools. Intelligent machines tools will have wide adaptability machining tasks and environment. Under the aim of people-centered, the machine decision-making and the man-machine coordinated, the 
intelligence function of intelligent machines is to implement the operation of multi-objective optimization including high efficiency, high quality, energy saving and low carbon and so on.

The Traits of Intelligent Machine Tools. Combined with the research of the manufacturing engineering laboratory which is attached to the American national standards institute of technology's comprehensive in 2003 and the United States intelligence processing platform (SMPI) in 2004, there are five features of the intelligent machine tools: (1) information perception; (2) behavioral decision; (3) quality assessment; (4) self-learning; (5) network communication.

(1) Information perception. Machine tool can be able to perceive its own state and processing ability, and have the ability of self calibration. In order to flowing, update and to be searched by operators conveniently, the information will be stored in different databases in the form of standard protocol.

(2) Behavioral decision. The machine can monitor automatically and optimize its operation behavior. It can find errors and correct the errors (self-calibration, self-diagnosis, self-healing and self-adjustment), and make it works in the best condition. Further, it can predict upcoming failure with the intelligent components and remind the need of maintenance and remote diagnosis.

(3) Quality assessment. Machine tool can assess the quality of machining. It can estimate the accuracy of the final product according to the data obtained in the process of processing or online measurement.

(4) Self-learning. The machine has the ability of self-learning and improving. It can update the application model of machine tool according to the data obtained after processing and processing (for example, the data obtained from measurement unit).

(5) Network communication. Machine tool can communicate with other machines without problems accordance with the general standard.

Conclusion, intelligent machine tools can monitor, diagnose and correct in the production process of all kinds of biases after understanding the whole process, and provide optimization scheme for production. It can also calculate the residual life of cutting tool, main shaft, bearing, allowing users to know their remaining time and replacement time.

The Structure of Intelligent CNC System Framework. Now, open intelligent CNC system mainly has four kinds of structure forms: all software model, based on the main line, a dedicated $\mathrm{CNC}$ and PC, industrial PC + motion control card and all have advantages and disadvantages. Full software of type, open the best, but it is too difficult to develop. Based on the general linear model, open better, but the required performance bus must meet the system requirements. For a dedicated $\mathrm{CNC}$ and PC, open poor. However, industry PC + motion control card in the form of numerical control system is good in openness and performance of the numerical control system.

In terms of intelligent $\mathrm{CNC}$ system structure frame, many domestic and foreign scholars proposed different structural frameworks. Literature [3] ATLURU et al. put forward a system framework of intelligent machine tool monitoring. Literature [4] Moriwaki et al. gave the structure of intelligent machine tools from kobe university in Japan. Moriwaki et al. pointed out the important technology of intelligent machine, including intelligent planning, making decision technology, intelligent monitoring technology and process control technology in the process of processing and so on. Literature [5] Zhanxi Yang proposed an open architecture framework of the open intelligent CNC system for industrial PC + motion control card from the Institute of Mechanical Science. The system is mainly composed of industrial PC, motion control card and multi-sensor system, etc. Combined with Moriwaki and Zhanxi Yang intelligent CNC system structure frame, this paper puts forward a new intelligent machine tool numerical control system structure frame, as shown in figure 1.

The system is mainly composed of intelligent algorithm to optimize system and sensor information acquisition system, etc. It uses intelligent process planning, decision-making, testing and other intelligent control technology. (1) Sensor information collection system is an important part of intelligent numerical control system. Sensor system collects the information during the machine tool processing (such as machining precision, etc.), extract and fusion after processing, and then provide processing results to the intelligent optimization module. (2) Intelligent optimization 
system calculates data from the sensor information collection system, and stores information that the computer can recognize after the translation. In addition, it can achieve information and exchange between CNC machine tools and the Internet or Intranet through networking, and achieve mutual contact between CAD and CNC, etc.

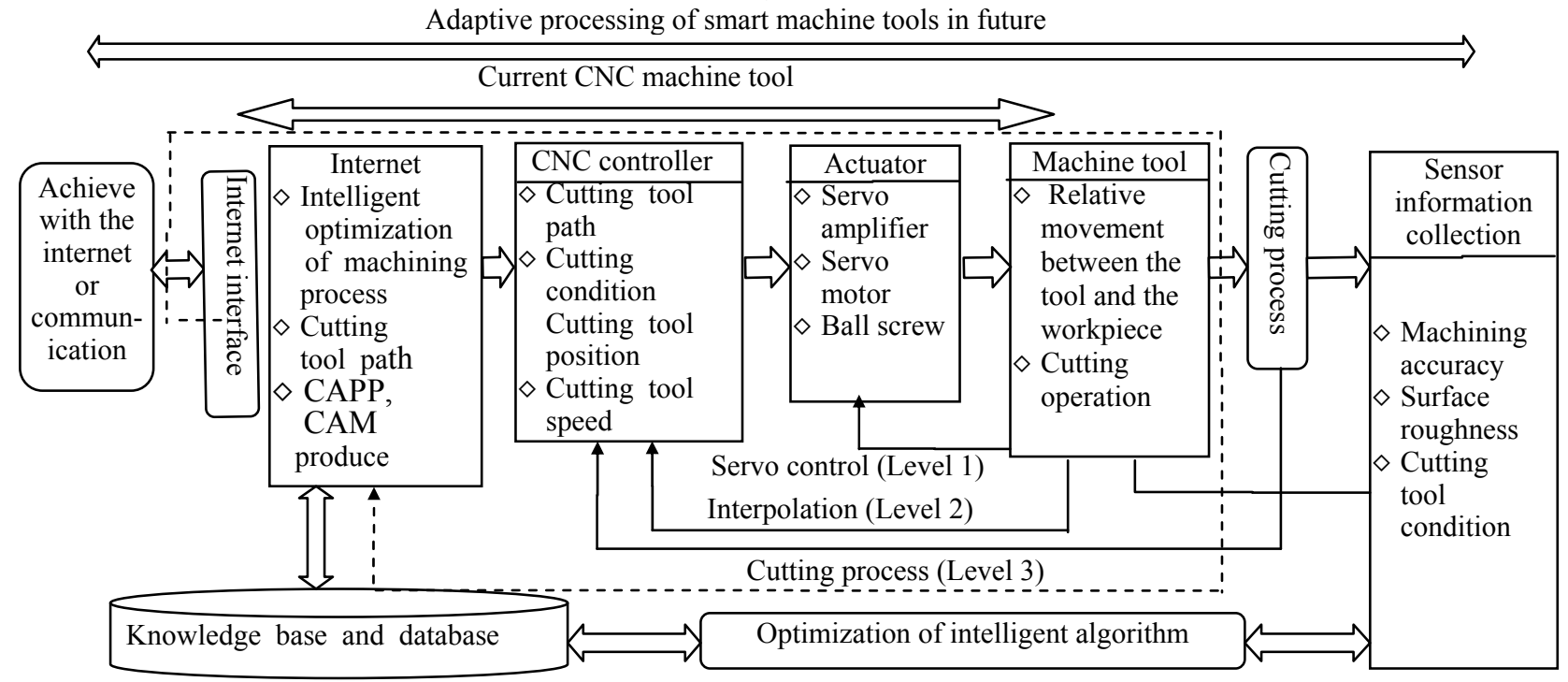

Figure 1 intelligent machine tool numerical control system structure

The main features of the intelligent CNC system: (1) It is easy to develop software and extend hardware with the current $\mathrm{CNC}$ machine intelligence technology and industrial PC + motion control card intelligent CNC system of openness. (2) It provides the foundation for achieving the intelligent control of machining process and the optimization of processing technology by the sensor information collection technology gathering all kinds of information in the process of CNC machine tool processing.

\section{The Application of Intelligent Machine Tools}

Intelligent machine tools have become indispensable equipment in manufacturing production and processing. At present, domestic and foreign researchers and manufacturers of intelligent machine tools made abundant research. The representative products are i5 CNC system of Shenyang Machine Tool Group and THINC intelligent machine tools of Japan.

(1) I5 CNC system of Shenyang machine tool group. After 5 years manufacturing spending 11.5 billion Yuan, Shenyang machine tool group developed the first i5 numerical control system machine tool with network intelligence in the world which can realize functions as follows: high precision and efficient in processing products, information management of workshop, creating the biggest value for customers; I5 system adopts international open real-time bus. Every machine tool not only achieves independent "thinking", but also participates in "group think"; Based on Internet and cloud manufacturing, on the side of the client, i5 system realizes intelligent factory, and at the point of after sale, it realizes the remote diagnosis and intelligent correction, which enterprise can carry out intelligent machine lease business in large-scale and recycle business for manufacturing operations, complete the transformation of manufacturer to service providers.

(2) THINC intelligent machine tools of Japan. Okuma believes that the design, implementation, and use of CNC system have been out of date at present, and the time for fundamental change has come. THINC not only make smart decision without human intervention but also keep increasing automatically the functions during the application of machine tools, and will be more adaptive to new environment change, more tolerance, more easy programming and using. In a word, the machine will lead to higher production efficiency without human intervention. 


\section{The Development Outlook of Intelligent Machine Tools}

(1) The basic research of intelligent machine tools technology problem. The related technologies of intelligent machine tools (such as STEP - NC, smart sensors, etc.) are much mature. However, some technical problems are lack of basic research, such as the acquisition of machine tool dynamic capability, measurement, processing and control integration, etc.

(2) The standardization of intelligent machine tools research. The realization of the function of intelligent machine tools needs to integrate information between the internal parts, but it is the relative lack of research on standardization of intelligent machine tools, so standardization research will be one of the future development trends.

\section{Reference}

[1] KOREN Y: Journal of Manufacturing Science and Engineering Vol. 119 (4B) (1997), p. 749.

[2] Print journalist: Machine tools and hydraulic No. (10) (2012). In Chinese.

[3] ATLURU S, HUANG S H, SNYDER JP: International Journal of Advanced Manufacturing Technology Vol. 58 (5-8) (2012), p. 566.

[4] Moriwaki T, Shirase K: International Journal of Manufacturing Technology and Management Vol. 9 (3-4) (2006), p. 209.

[5] Zhanxi Yang, Qiushi Han: Manufacturing technology and machine tools Vol. 12 (2008), p. 65. In Chinese. 